\title{
BMJ Open Living with dementia with Lewy bodies: an interpretative phenomenological analysis
}

\author{
Victoria Larsson, ${ }^{\oplus 1}$ Axel Holmbom-Larsen, ${ }^{1}$ Gustav Torisson, ${ }^{2}$ \\ Eva Lena Strandberg, ${ }^{3}$ Elisabet Londos ${ }^{1}$
}

To cite: Larsson V, HolmbomLarsen A, Torisson G, et al. Living with dementia with Lewy bodies: an interpretative phenomenological analysis. BMJ Open 2019;9:e024983. doi:10.1136/ bmjopen-2018-024983

- Prepublication history for this paper is available online. To view these files, please visit the journal online (http://dx.doi org/10.1136/bmjopen-2018024983).

Received 25 June 2018 Revised 21 November 2018 Accepted 18 December 2018

Check for updates

(C) Author(s) (or their employer(s)) 2019. Re-use permitted under CC BY-NC. No commercial re-use. See rights and permissions. Published by BMJ.

${ }^{1}$ Department of Clinical Sciences, Malmö, Clinical Memory Research Unit, Lund University, Malmö, Sweden ${ }^{2}$ Department of Infectious Diseases, Skåne University Hospital, Malmö, Sweden ${ }^{3}$ Department of Clinical Sciences, Malmö, Center for Primary Health Care Research, Skåne University Hospital, Lund University, Malmö, Sweden

Correspondence to Dr Victoria Larsson; victoria.larsson@med.lu.se

\section{ABSTRACT}

Objective To explore the subjective experience of living with dementia with Lewy bodies (DLB).

Design A qualitative study of in-depth interviews using interpretative phenomenological analysis.

Setting A memory clinic in Malmö, southern Sweden. Participants A purposive sample of five male participants with DLB between the ages of 78 and 88 years and disease duration of $1.5-7$ years.

Results Three themes were identified in relation to the participants' experiences of living with DLB: (1) disease impact, in terms of symptom experience and restricted participation and activities; (2) self-perception and coping strategies; (3) importance of others, such as healthcare, family and friends.

Conclusions This study provides a broad insight into the first-hand experience of living with DLB and how it compares with other dementia types. Findings highlight factors characterising the disease experience and wellbeing, and how persons with DLB address challenges arising secondary to disease. These findings are important for both research and clinical practice, demonstrating the feasibility of direct involvement of DLB persons in identifying important aspects of care, which include improved healthcare services.

\section{INTRODUCTION}

Dementia is an umbrella term for a group of disorders that have an impact on cognition, memory and activities of daily life, affecting approximately 47 million globally. ${ }^{1}$ Dementia with Lewy bodies (DLB) is the second most common type of neurodegenerative dementia after Alzheimer's disease (AD), accounting for $7.5 \%$ of dementia diagnoses in secondary care, although many cases are still believed to be missed or misdiagnosed. ${ }^{2}$ Widespread neuropathological changes are found in DLB, resulting in certain clinical characteristics. ${ }^{3}$ The cognitive decline is dominated by visuospatial and executive dysfunction, in comparison with memory and orientation deficits often associated with other dementias. There are four core additional symptoms: (1) fluctuations in cognition, attention

\section{Strengths and limitations of this study}

- Interpretative phenomenological analysis was used in order to explore the first-hand experience of living with dementia with Lewy bodies.

- A small purposive sample was used to acknowledge rich accounts of illness experience.

- Interviews were broad and flexible in nature and allowed participants to bring up topics of personal relevance, and were conducted in the participants' homes to create a relaxed non-medical environment.

- Transferability was affected by excluding non-Swedish speakers and by not identifying any suitable women for the study.

- Researchers with varied competencies and backgrounds were included to minimise potential bias due to clinical preunderstandings in the data analysis; however, other triangulation or member checking was not used.

and wakefulness; (2) animated and detailed recurrent visual hallucinations; (3) rapid eye movement (REM) sleep behaviour disorder leading to recurrent violent dream enactment; (4) parkinsonism, involving rigidity, slowness and frequency of falls. ${ }^{3}$ This is a complex clinical picture, associated with distinct challenges compared with other dementia types in terms of clinical management and care, ${ }^{4}$ which is indicated by higher caregiver burden ${ }^{5}$ and poorer quality of life. ${ }^{6}$ With no prevention or cure, the mainstay of care currently consists of providing symptom relief and meeting care needs in order to improve well-being for the persons and caregivers living with the disease.

The constituents of well-being in DLB, as well as the preferences of patients and their caregivers, have not been extensively investigated. Most research in the field has traditionally focused on biomedical aspects of the disease, ${ }^{7}$ and most trials still base their recommendations on statistical rather than clinical significance, failing to take into account patient-related outcomes and the views of 
patients or caregivers. ${ }^{8}$ Studies which have intended to address the wider impact of DLB disease have focused primarily on caregiver distress and burden. ${ }^{9-12}$ The perspective of the person living with disease has consequently been overlooked, and viewpoints which are important for guiding clinical care and to truly develop effective clinical interventions have been missing.

One way to address these issues is to conduct research providing personal narratives and first-hand reports of what is it like to live with a condition and the response to this experience. ${ }^{13}$ Using qualitative methodology such as in-depth interviews would probably be the most suitable approach, having the advantage of being able to explore the complexities of these matters in detail. To date, there are no such studies involving specifically persons with DLB. Whether or not persons with DLB are able to participate in this type of research, in view of cognitive and psychiatric symptoms, therefore remains an unanswered question. In comparison, lived experience has been reasonably well investigated in people with unspecified dementia or $\mathrm{AD}$, where specific aspects have been explored such as coping strategies, impact on awareness, self and identity. ${ }^{13-15}$ The generalisability of these findings in persons with DLB can however be questioned in view of the diverse cognitive, psychiatric and motor features described, expected to be reflected in the subjective disease-experience.

Therefore, this study aims to conduct a preliminary exploration into the subjective experience of living with DLB. Through in-depth interviews, the feasibility of involving persons with DLB in such research will be assessed for the first time. The analysis will further address a specific objective of identifying factors influencing disease-experience and well-being, information which is important to communicate to caretakers and healthcare professionals in order to improve the understanding of this patient group.

\section{METHODS}

The study was reported according to the Standards for Reporting Qualitative Research. ${ }^{16}$

\section{Setting and participants}

Purposeful sampling was used to increase the likelihood of including participants able to provide a rich account of their particular experience. To be considered for the study, participants had to be (1) diagnosed with DLB according to consensus criteria ${ }^{17}$; (2) current patients at the Memory Clinic, Malmö, Sweden; (3) able to consent to the study; (4) community-dwelling and (5) Swedish speaking. Suitable participants adhering to these criteria were identified by the senior physician responsible for patients with DLB at the Memory Clinic (EL).

VL then contacted the identified patients, explaining the study and offering participation. Participants were recruited for as long as more information was deemed necessary for the analytical process. Out of six persons approached, only one person declined participation, reason being not having the time. The five participants were all white men between the ages 78 and 88 years. At the time of the study, no women were identified meeting the inclusion criteria, demonstrating the male predominance in DLB ${ }^{18}$ All but one lived with their spouse. At the time of the interviews, disease duration since diagnosis was between 1.5 and 7 years.

Two quantitative measures were used to characterise the participants of this study. Cognitive level was assessed by the global screening instrument mini-mental state examination (MMSE). ${ }^{19}$ The MMSE was performed as part of clinical practice prior to the interviews and recorded scores among the participants were between 18 and 29 points, indicating mild to moderate cognitive impairment. After the interviews, participants also completed a Quality of Life-Alzheimer's dementia (QoL$\mathrm{AD})$ questionnaire. ${ }^{20}$ The scale consists of 13 items rated on a scale from 1 to 4 , with total scores ranging between 13 and 52, and higher score reflecting a better quality of life. QoL-AD was used to provide a quantitative measure of perceived quality of life with scores ranging between 21 and 42 points. This indicates that participants had varying levels of cognitive function and subjective quality of life. Further demographic information has been concealed to protect confidentiality.

\section{Data collection}

All interviews were conducted face to face by VL in the participants' homes between December 2015 and June 2017. Participants were encouraged to be interviewed alone, enabling speaking freely without influence of another person. In one case, this was not possible due to patient request and the spouse was present throughout the interview. In-depth interviews were conducted, each interview starting with an open question "Could you start by telling me a little bit about yourself?". Thereafter, the interviews took form of a conversation, using reflection and open-ended questions to facilitate a flexible discussion. There was no strict interview guide, but prompts and questions were used to explore the illness experience, as well as barriers and facilitators of well-being. Participants were allowed to guide the interviews to topics of personal importance with the interviewer following lead. Examples of questions asked in the interview are shown in box 1 .

The interviews continued until the open-ended questions did not give rise to any new information or understandings. The duration of interviews was between 60 and $134 \mathrm{~min}$. A break was offered, to accommodate for tiredness secondary to their disease; however, this was not needed for any of the participants. No repeat interviews were conducted. All interviews were audio-recorded and transcribed verbatim by a professional medical secretary. Transcripts were checked for accuracy by VL re-listening to the interviews. Transcripts were not returned to participants and they did not comment on findings.

Previous research has outlined a number of challenges in conducting in-depth interviews with people 


\section{Box 1 Example of interview questions}

\section{Questions}

Can you tell me about yourself?

Is today a good day? Why is that so?

Can you tell me about the symptoms of your illness?

Is there anything you have started or stopped doing because of your illness?

What do you spend your days doing?

Is there anything that would make your life better the way it is now?

What would you change about your current situation if you could?

What makes you happy or makes life worth living?

How do you consider your quality of life?

with dementia, again with a focus on people with $\mathrm{AD} .{ }^{21}$ Considering the differing symptomatology in DLB, other challenges were expected. For this reason, field notes were constructed after each interview commenting on difficulties experienced by the interviewer. Overall, participants took interest and engaged well with the interviews. At times cognitive difficulties influenced the interviews, however not necessarily due to memory deficits as has been seen in $\mathrm{AD},{ }^{22}$ but rather in losing train of thought and due to cognitive fluctuations. Unclear speech elaborations occurred at times, but it was found that participants would eventually return to their principal thought if not interrupted. For this reason, plenty of time was offered to answer each question posed and for the interview as a whole, to avoid missing significant information. Many participants had soft and slow speech (due to parkinsonism), which could lead to sentences being inaudible or difficult to interpret. This was addressed by asking the person to repeat himself, which also applied if the person appeared vague or unclear for other reasons. Contrary to our prior hypothesis, interviews were not terminated prematurely due to excessive tiredness.

\section{Patient and public involvement}

Patients and public were not involved in the development of this study.

\section{Data analysis}

Interview data were analysed using interpretative phenomenological analysis (IPA). ${ }^{23}$ This method of analysis serves to highlight the participant's subjective perceptual processes involved in making sense of their life situation, consistent with the epistemological position of our research question. In terms of the analytical process, IPA shares elements with many other types of thematic analyses, aiming to identify, analyse and report patterns within qualitative data. ${ }^{24}$ However, IPA comes with specific theoretical commitments which are based on phenomenology, hermeneutics and ideography. ${ }^{23}$ In short, this means that IPA will give experience primacy (phenomenology) and aspire to understand this experience in great detail (ideography), while also recognising that this involves an interactive and interpretative interplay between participant and researcher (hermeneutics). ${ }^{25}$ By assuming a link between verbal reports, thoughts and physical experiences, IPA has been recognised as a particularly useful method for evaluating people's response to illness ${ }^{25}$ and is therefore frequently used in health research.

The first phase of analysis consisted of VL, EL and AH-L reading through the full transcripts to the point of being fully immersed in the data, to be familiar with both breadth and depth of the content. Notes were made throughout the process, and relevant units of meaning and emerging themes of interest were identified. Themes were identified as those aspects of the data that captured something important in relation to the research question. Transcripts were coded accordingly, and a list of preliminary themes was generated. Transcripts were then re-read several times until the authors ensured that the list was comprehensive and that relevant extracts were compiled for each theme. All data were coded manually, rather than using a software program.

At this point, a fourth researcher (ELS) was involved, to provide a validity check of analysis and interpretation. ELS has expertise in qualitative research and read all the transcripts to support the remaining analytical process, including defining the final themes and manuscript preparation. This review process was iterative, processing back and forth between themes and raw data in order to reach a collective agreement around the important patterns, and to confirm the internal homogeneity and external heterogeneity of the themes. ${ }^{26}$ Several versions were constructed before deciding on the final thematic structure. Examples of data extracts with their coding and final theme are shown in table 1.

In the presented extracts throughout the manuscript [...] indicate that some text without substantial importance has been removed, while ... without brackets indicate silence within a sentence. All data analysis was conducted in the Swedish language using the original transcripts. Extracts were translated only in the write-up phase by VL who is native to the local region and has lived many years in the UK. The translation from Swedish has been kept as literal as possible, except where minor modifications have been necessary in order to preserve conversational style, idioms, colloquialisms or level of affect.

\section{FINDINGS}

Three overarching themes were identified in the participant accounts, characterising their experience of living with DLB: (1) disease impact; (2) self-perception and coping strategies; (3) importance of others. Each theme will be described in detail in separate sections.

\section{Theme 1: disease impact}

Chronic illnesses are characterised by symptoms resulting in secondary consequences which can influence wellbeing. ${ }^{27}$ The content of this theme highlights the ability and willingness of participants with DLB to describe, in their own voice, the experience of these symptoms and what difficulties emerge as a result. 


\begin{tabular}{|c|c|c|}
\hline Data extract & Coding & Theme \\
\hline $\begin{array}{l}\text { Yes... it is called Lewy body dementia but I think that's so rotten... if you tell colleagues } \\
\text { then they change so that you have Lewy body dementia so they... then... then they will } \\
\text { put a mark in your forehead... dementia that's no point... no point in telling him... that's } \\
\text { too complicated... he will never get it... or a joke or something funny... there's no point... } \\
\text { he won't get it anyway... and... it's not true... because you will... I think but maybe the } \\
\text { surroundings don't... but they... in your own eyes... you have to protect yourself... in your } \\
\text { soul... against this... dementia... mark [3] }\end{array}$ & Stigmatisation & $\begin{array}{l}\text { Self-perception } \\
\text { and coping }\end{array}$ \\
\hline $\begin{array}{l}\text { Important in life... very... existential question (mumbles) ah, what is important in life... } \\
\text { damn... what can I say? Yes... just live! [...] Yes... what can I do about it... there's nothing } \\
\text { to do then... more than maybe I could improve the possibilities of living a little bit longer... } \\
\text { but probably you can't... not at least in my time right... but I will have to live the life I can } \\
\text { live... I can't understand how you can think in any other way... we live in the now... you } \\
\text { can't live somewhere else [1] }\end{array}$ & Acceptance & \\
\hline
\end{tabular}

\section{Symptom experience}

Compared with accounts by other people with dementia, ${ }^{13}$ a wider spectrum of symptoms was described by the participants of this study, with less emphasis on memory and orientation problems. Cognitive complaints were however articulated, and recognised in terms of forgetfulness, difficulties remembering names, struggle in keeping up in conversation, being inactive or passive, having slower thoughts and visuospatial problems. Most participants demonstrated insight into the complexities of their own cognition and how this was influenced by fluctuations, which could render a feeling of frustration. Fluctuations were expressed as symptoms coming or going, variation in attention or the feeling of suddenly losing their train of thought. One participant described his cognitive symptoms like this:

I don't think myself that I am particularly memory deficient... I have to say... I have on the other hand become slow... I think a little slower... sometimes I forget... a key word which I am going to say... yes... when I talk to people and that... but it comes soon... in a minute or so I can fill in what was missing... that's what it's like still [3]

Physical changes were highlighted, with accounts of unsteadiness, stiffness and slowness, sometimes leading to frightening experiences. Excessive tiredness was profound for some, needing and sometimes debilitating to life with lack of improvement with pharmacological treatment. Frightening nightmares were also described, as well as difficulties in separating dreams from reality, indicative of REM sleep behaviour disorder. One participant described how the dream enactment meant that he "didn't even want to go to bed [4]", and another how terrible anxiety would be "left from the dream [3]" even after waking up. Others described a natural resolution of these symptoms over the disease course. Participants would also, with caution, reveal seeing things that were not there, indicative of visual hallucinations. Insight was retained during the description of illusions and hallucinations. The emotional response could vary from fear to relative indifference:

That you... see a person... in... in... in the room... maybe I have hung... my clothes on some... on some hanger so that it shapes a person... and then... it follows... so suddenly that person starts walking and become very real... but then... well... it is not unpleasant... not so that I am scared or anything like that [5]

There were also descriptions of other symptoms-dropping their blood pressure when standing up (orthostatic hypotension), problems with peeing (urinary incontinence), finding it difficult to swallow (dysphagia) and feeling low in mood (depression) - all which are recognised symptoms in DLB, demonstrating an ability to self-report symptoms.

\section{Restricted activities, participation and relationships}

A distinct variation was seen in the experience of symptoms between participants and to what extent a symptom would impact on life. A common denominator was however that the most troubling symptom would be significantly restrictive in character and limit activity, participation and social engagement. Many participants experienced deteriorating motor function with worsening gait and balance, resulting in falls and injuries. Participants' accounts would indicate subsequent fear of falling, which in turn led to risk behaviours such as moving around slower, using walking aids or completely refraining from leaving the house. This would be amplified in the presence of external barriers, such as outdoor environments not supporting participants' requirements, for example, lack of wheelchair access and uneven pavements. Reduced mobility would diminish independency and self-sufficiency, and also prevent travelling to visit 
friends and family, leading to increasing isolation and reduced quality of life. Participants also depicted personal psychological barriers, for example, not attending an event because of the potential social inconveniences that would arise, and a sense of being a burden:

I get worse in my balance... when I was like that... then people are rushing to help me... I was probably sitting five rows down or three... and then people will help me up the stairs... and then the wheelchair is up there... then there's no problem... there are elevators... and the mobility services work... but I want it less and less... I don't want to go there... I think it... it causes such hell of a sensation... people needing two living supports to get somewhere [3]

Cognitive deficits also contributed to limited interactions with others. In other studies, this has often been attributed to memory or language deficits, affecting communication with others. ${ }^{28}$ For the participants of this study, the primary cognitive culprits were instead identified to be excessive tiredness, reduced mental speed and passivity, which was described as risk of falling asleep, not following conversations and reduced interest in the social situation. These cognitive barriers, limiting meaningful interactions, could ultimately result in withdrawal from social settings:

I am... unfortunately very lonely [...] yes... I had this card playing gang... but I've let that go because I can't hear what they say... I think I told you before... so I can't give fun replies to jokes [...] it passes by... it goes so quickly so that when I have finally come up with what reply I am going to give... then they have already moved on [...] I don't go there anymore [...] It is sad... very sad [3]

Overall, there was a recognition that the disease process generates a wide range of symptoms, which are challenging to the person due to the resulting physical and social consequences. These potential losses would however also be influenced by personal qualities, attributes and beliefs of the person living with disease, representing a psychological aspect of disease experience, outlined in theme 2.

\section{Theme 2: self-perception and coping strategies}

The experience of self in dementia has been described widely in the literature and is a complex concept. ${ }^{1529-32}$ There is no consensus of how to define self in dementia, with various theoretical models proposed, as well as a continuous debate as to what extent the self persists or diminishes in people with dementia. ${ }^{15}{ }^{30-35}$ For the purpose of this study, self has been defined broadly as a multifaceted concept including sense of identity, personal beliefs about one's attitudes, skills and traits, as well as the self being a reflection of interactions with others. A sense of self was identified in all participants throughout the interviews, regardless of cognitive dysfunction, suggesting that this does not necessarily weaken because of DLB disease. Take for example how one participant, while describing disease-related changes, also expresses sense of self:

So that... the disease has taken a place in my life of course... it... and I regret that I can't cycle and drive the car and those things... it... it has been the big change really in my life... that I can no longer get out. In forests and land in the same way as before... I am a nature person who listens to small birds and big birds and animals on the whole [5]

\section{Threatened self-perception}

Disease-related changes, both cognitive and physical, were found to threaten self-perception, in the way that they were felt to influence identity, skills and traits. Cognitive function, in particular memory, has been identified important for sense of self, as it is important for the personal narrative. ${ }^{33}$ One participant described his concerns:

I noticed a difficulty in remembering names... this is what I was most worried about... because it wasn't... well... it was my memory... which is the part of my body that I have been working the most with [2]

Physical or cognitive changes could also lead to an inability to provide for the household, being less accountable and having less responsibilities. This could threaten the perceived self and create a feeling of being a burden for those around, as expressed by one participant:

It is tiresome for my spouse [...] We would both be better off $[\ldots]$ Well... I have been in heaven here when she has been managing it [...] It will be a little different to come to a place where... group living... yes... well I have to take the consequences of that $[\ldots]$ As we are... my spouse is locked down as a result... if she need to drive... she doesn't dare being gone for too long [4]

Sense of self was also affected by how participants believed others viewed them and their illness. Some expressed how the dementia term, and how they thought others interpreted this, was problematic. The word was related to stigmatisation and sometimes the feeling that others would only approach with caution:

Participant: Now everyone knows that I have a disease right but we never speak about it... then you have to be a bit more pally so to say

Interviewer: Why do you not talk about it?

Participant: Insecurity? What can you say? It is embarrassing?

Interviewer: For you or for them?

Participant: For them... maybe they think it's embarrassing for me too

Interviewer: Would you think so?

Participant: No... I have a disease here in the head and it causes some problems and so on... but I live 
a life... I know what my name is... it is a lot I don't know anymore but that doesn't matter [1]

Another person described it as having a "mark in your forehead... dementia that's no point... he will never get it [3]", indicating a feeling that others can assume that dementia inevitably implies a loss of function to a point where meaningful interaction is no longer possible. Participants generally expressed a belief that those around, such as family or colleagues, have an exaggerated or mistaken view of what the disease actually entails. This was sometimes associated to perceived physical and psychological exclusion, contributing to loneliness and unhappiness. Facing this, some participants maintained empathetic to those around who they felt did not understand them, suggesting intact mentalising processes and emotional cognition:

I have friends who... who will say 'can you find the toilet'... that's a given right... that I can find the toilet... I have been there several times right... but obviously they have all the reasons for suspecting that I would not be able to find the toilet if I am sick and strange right... so that... it's hard [1]

\section{Strategies and coping}

Despite negative experiences due to the illness, some participants maintained an air of optimism and declared a sense of well-being. These participants were identified to adopt strategies and coping mechanisms to handle symptoms and threats to self-perception, and in doing so refused to passively accept disease-associated changes. This is similar to findings in the wider field of dementia, ${ }^{14}$ and contests a view often portrayed by the public, where persons with dementia are simply submissive sufferers. A number of specific strategies were identified, which served to promote positive self-perception and sense of coherence. These involved active fighting strategies such as emphasising personal attributes and seeing yourself as an active contributor, as well as strategies protecting the self by acceptance, letting go of control or avoidance.

Some participants talked about being fundamental optimists and reflected the importance of valuing their own personality and attributes. This included expressions such as "deciding to have a smile on my lips [5]" and communicating the importance of claiming responsibility for their own happiness and to give life a meaning. Most talked about this as an attribute from the past, which was interpreted as something they continued to actively engage throughout their disease course. Another active strategy to demonstrate self-worth was to stand up for yourself in the case of maltreatment, exemplified by this otherwise negative healthcare system encounter by one participant:

There is a really long corridor stretching though the whole house [...] And then he remembered that he bloody well was going to speak to me too... so then he screamed... so that it echoed through the whole building there 'you there... don't forget to increase that... those tablets you're taking... you should take three instead of two!' [...] I thought that was so incredibly tactless... stand there and scream in the entire corridor in that... eh... indiscrete really indiscrete way... I was deeply deeply affected by this [...] I was then invited for a return visit and I phoned and said 'I never want to meet that man' [...] So I ended the contact [3]

Some participants had active roles that they were striving to maintain regardless of the disease process. By doing so, participants would resist the notion of becoming passive bystanders throughout the disease course. This was particularly prominent in one participant who was still working, where the interview would largely focus on different strategies to allow him doing so:

Participant: Without it I would have been dead

Interviewer: Do you think so?

Participant: Yes, I definitely think so... braindead

Interviewer: How do you mean?

Participant: Well... you have... it is what I think about every day... and I look into the future all the time... we are growing and growing... and the growing one is me [2]

Other participants would find or develop new roles. This could involve joining clubs or societies to seek out new acquaintances and resist isolation, or even partake in dementia research, anything where a meaningful role could be found.

For many, one way of coping with disease-related changes would be to acceptance and focus on the present, rather than future or past, without judgement. Acceptance involved that of changes in self, or personal identity, due to disease:

I have always despised people who don't work hard and who slept... and now I sleep a lot... and I feel that when I wake up in the afternoon... then I'm on the ball [2]

Acceptance also comprised adjusting general expectations and appreciating the good things in life, as it has become, despite illness and ageing. Part of this encompassed constructing new values in life to better suit current function and situation, such as one participant who reasoned like this:

Interviewer: Is there something else that you feel you can no longer do that you used to do?

Participant: I can no longer drive a car [...]

Interviewer: Do you miss it?

Participant: Well not really... no I don't... I shouldn't drive a car... why would I do that... it is foolish to drive a car [1] 
Another aspect of acceptance was to let go of control, and instead allowing the spouse or healthcare professionals to be in charge of care. For some participants, this insight came as a surprise as it did not reflect their ordinary personality. However, by liberating oneself from the responsibility of the illness, participants could perhaps focus more on positive aspects of life, despite deteriorating function.

\section{Theme 3: importance of others}

Preservation of self throughout the disease course has been described to require the cooperation of others, making the self vulnerable to the actions and behaviours of others. ${ }^{35}$ While positive actions from others can be helpful in maintaining sense of self, a malignant social environment can therefore have detrimental effects. ${ }^{36}$ From our participants' accounts, it was identified that the actions of others would consequently be relevant for the overall disease experience and well-being.

Interactions with healthcare played a particular part for many and the varying encounters, good and bad, would be narrated throughout the interviews. Varying levels of negative experiences would be portrayed with situations where the respect for the person was overlooked would particularly result in an overall poor relationship. One participant described how around the time of his diagnosis "the children were summoned and he (the doctor) gave a lecture on how badly I would end up [...] to quickly deteriorate and become a demented old man [3]", undermining the participant's autonomy. A number of participants also experienced lack of competency around the DLB diagnosis. This was sometimes also associated with experiencing a delayed diagnosis and inappropriate or lack of treatment, something which was negatively perceived and created insecurity.

Contrary to this, others would describe healthcare interactions where respect and shared decision-making served as the foundation. Respect was interpreted to be conveyed in the communication style; listening, engaging with person and relatives, using lay-man terms and reasoning. One person described his experiences:

I have never seen such a doctor... do you understand... she was remarkably normal right... she would talk as if she talked with anyone or anything right $[. .$.$] Yes it was really good... totally fantastic...$ and then she said 'I can take you on' and that was completely something else [...] She pays... sorry... she behaves as any other person right... those bloody doctors don't... they come there and swank... most of them do... don't they? [1]

To be treated with respect, regardless of the illness, was linked to trust. Within the healthcare services, structural matters such as good availability and regular communication were identified to ensure a trusting relationship. Within the personal sphere, the spouse was often described as providing physical and psychological care, as well as reducing the need for formal caregivers in the home. Other relationships were also classified as important, and although they rarely bore the equivalent significance of a partner, they would be important means for allowing social participation and partaking in activities outside of the home. The flip side of trusting others would be the resulting vulnerability since loss of this person could result in both despair and isolation:

I have met a... girl I have to say [...] And she was employed by... social services... is that the name? [...] She came and sometimes didn't... and then we ended up on speaking terms... and so we... she has been very very helpful... extremely helpful and driven me around in the wheelchair without complaining... in sun and rain and we have been to the cinema lots of times... and we have been to... yes... concerts $[\ldots]$ It is more or less over [...] She switched jobs [...] So that... I am unfortunately very lonely [3]

Social and psychological isolation was expressed and viewed as negative consequences of the illness, with less friends, family or former colleagues reaching out or wanting to remain in contact. For the eldest of the participants, there was also an acknowledgement that age itself would lead to a natural reduction of friends and acquaintances.

\section{Overall results}

Conceptually, the three themes outlined are thought to be dynamically related rather than independent to each other. Figure 1 illustrates the imagined sequence whereby the disease process generates symptoms which lead to a change in function and behaviour (theme 1). These changes can in turn threaten and alter self-perception, leading to a need for developing coping strategies (theme 2). This relationship is envisaged as bidirectional, in that internal processes regarding self-perception can similarly influence the consequences of disease. Moreover, external processes such as family, healthcare and society will feed into the sequence, also having an effect on self-perception and the disease experience (theme 3).

\section{DISCUSSION}

This study provides a broad insight into the first-hand experience of living with DLB and demonstrates the feasibility of conducting in-depth interviews in this patient population. Three major themes were identified from the interviews: (1) disease impact, in terms of symptom experience and restricted participation and activities; (2) self-perception and coping strategies; (3) importance of others, related to respect and trust for those around. While previous qualitative studies in persons with dementia have elicited similar concepts to those found here, ${ }^{1314}$ no study has explicitly focused on persons with DLB. Specific findings in this study include a greater variety in symptoms, leading to different barriers influencing well-being. For example, previous studies have attributed loss of confidence in moving outside due to fear of getting lost, ${ }^{37}$ while 




Figure 1 Experience of living with DLB. The ongoing disease-process is generating symptoms influencing function and behaviours. This leads to secondary consequences relating to sense of self and well-being, a relationship which is bidirectional. External processes can feed in to this model, in turn influencing lived experience and sense of self.

the participants of this study identified fear of falling and risk of being dependent on others as the major concern. Similarly, participants expressed not being able to partake in social situations because of the slowness in articulating thoughts and not keeping up to speed with the conversation, rather than not knowing or remembering what to say. Furthermore, the first-hand descriptions of the wider symptom complex such as sleep disorders or visual hallucinations have been relatively absent from the literature, which is important as they characterise the illness experience in DLB. It also highlights the importance of symptomatic relief for a wide array of symptoms, including those which are non-cognitive in nature and sometimes under-recognised. ${ }^{4}$

Well-being has traditionally been defined using a biomedical approach where quality of life has been assumed linear to physical and cognitive functioning. For persons with a progressive neurodegenerative disorder, this view would imply that quality of life decreases as the condition worsens and that good quality of life cannot be achieved in presence of these deficits. ${ }^{38}$ This study, and the works of others, suggest that this disease-orientated approach is inaccurate. ${ }^{9-41}$ Instead, well-being is better defined, as suggested by $\mathrm{WHO}^{42}{ }^{2}$ as a composite of physical, psychological and social well-being. The findings of this study are in line with this view, demonstrating that the impact of disease entails more than the experience of symptoms alone. For example, although DLB leads to deteriorating physical function and reduced mobility, it is the effects on social engagement which was demonstrated to be primarily linked to well-being, similar to findings in other patient groups. ${ }^{43} 44$ This can be encouraging as it means that well-being is not simply a result of illness itself, and could therefore be both dynamic and modifiable, despite progressive neurodegeneration. Hence, factors unrelated to the disease process could counteract the consequences of the disease.

Similar to studies in other progressive illnesses, this study showed that DLB disease can threaten self-perception due to the struggles and losses of physical, social and psychological character, leading to loss of self, reduced self-worth, withdrawing behaviours and non-participation. ${ }^{152734}$ This necessitates the development of coping strategies in order to go through this process and still maintain the qualities that attribute and define you as a person (theme 2). Active contesting strategies consisted of standing up for yourself, demonstrating your own worth, reaching out to others or finding new motivations and roles. Others would foster strategies of acceptance of the current situation, or even avoidance and withdrawal. This also included adapting to the current situation, adjusting life goals and reappraising one's ability and altering expectations, which are general strategies recognised in the literature to avoid disappointment. ${ }^{45}$ Because sense of self is part of a social process, the person is confronted with the task to find a meaningful role in their transformed social context. For participants in this study who employed this strategy, it manifested as exploring novel or different responsibilities or seeking out other enjoyments or social connections, in order to promote positive self-perception. Managing the changes in self-perception, using successful coping strategies, can therefore be considered as one way of improving well-being in DLB.

The disease experience was also dependent on the cooperation and support from others; family, friends, healthcare and society (theme 3). Feeling misunderstood or not respected by others would lead to behaviours such as withdrawal, avoidance, lack of trust and inflamed self-perception. In contrary, avoiding disempowerment, labelling or depersonalisation would enhance respect and trust. Participants recognised that the progressive nature of the neurodegenerative disease would require help from others to support functions of daily living. However, there was a wish for this support to be given respectfully and at a level of the ability of need in order to maintain independence, dignity and sense of self, similar to findings in studies of other people with dementia. ${ }^{46}$

A purposive and fairly homogeneous small sample was selected according to the recommendations for using IPA, allowing full appreciation of each participant's account. ${ }^{23}$ Some variation was demonstrated in cognitive level and subjective quality of life measured with QoL-AD, meaning that differing perspectives were viewed. With only slight information added by the final interview, sample size was deemed adequate for the purpose of this study. Nevertheless, in view of the broad symptom 
and severity spectrum of DLB, part of the study findings might not be generalised to the entire DLB population, but are primarily applicable to patients resembling those within this study. Transferability was affected by excluding non-Swedish speakers and by including male participants only, due to not finding suitable females for the study. The homogeneity in living situation could also influence the results, with all five participants living at home where four together with a spouse. Furthermore, verbal communication was well preserved perhaps suggesting a milder disease stage. However, it should also be recognised that persons with DLB can have an unpredictable disease trajectory, where the disease stage can be difficult to identify using current parameters. This was manifested in this study population, as one participant unexpectedly passed away only few weeks after being interviewed.

Interviews were conducted at home to create a relaxed non-medical setting, making the participants comfortable to talk about their experiences on a personal level. In view of the exploratory nature of this study, the interviews were flexible and guided by the participants which was an advantage as there was no prespecified agenda. It was recognised in the planning stages that although VL did not have a prior relationship with the participants, being a doctor and a PhD student affiliated to the memory clinic could itself influence the interview situation. ${ }^{47}$ However, the presence of strong negative perceptions indicate that participants still felt free to express their views. Conducting repeat interviews would have been useful for validity and credibility, and to give an opportunity to assess consistency in the views expressed, particularly with regards to cognitive impairment. Repeat interviews could also have addressed longitudinal illness experience, something which was disregarded in this study.

IPA is a flexible and versatile research approach for understanding people's experiences and how they make sense of these. ${ }^{25}$ It has been widely used in health research and deemed suitable for the research question. Findings were presented together with quotes from the participants, to illustrate that pre-existing theoretical concepts were not imposed on the participants' experiences, ensuring integrity of the analysis. Nevertheless, IPA involves an interpretative analytical process, meaning that viewpoints and pre-existing understandings within the research team can bias the analysis and final results. ${ }^{24} \mathrm{VL}$ and AH-L are clinical doctors and EL is a senior clinician and professor in cognitive disorders, all with experience of patients with DLB. In addition, EL has a prior relationship with the participants which could influence the analysis. However, ELS is an associate professor in community medicine and has expertise in qualitative research but not in DLB, and therefore helped minimise the bias that the clinical preunderstanding of the others could cause as well as ensuring that the final themes covered all data.

\section{Implications}

Despite increased emphasis on user involvement, there are few studies focusing solely on the views of DLB persons in terms of illness experience, care and treatment, contributing to ignorance and stigma. ${ }^{8}$ The findings demonstrate that persons with DLB are able to provide relevant accounts in an interview setting, which is encouraging and should influence both qualitative and quantitative research in the future.

Findings in this study also have implications for clinical practice. Ignorance within the healthcare setting was identified to result in delayed or incorrect diagnoses and subsequently inadequate treatment, similar to findings in a survey-based study. ${ }^{10}$ Further clinical support and educational resources are therefore required for those settings where persons with DLB can be encountered, including both primary and specialist care settings. Continuous care should ideally be provided by physicians experienced in the complex management of these patients. Other than pharmacological management, persons with DLB might also benefit from counselling, psychological support or goal-oriented rehabilitation, ${ }^{48}$ particularly since this study has demonstrated the use of coping strategies to manage disease-related changes.

The experience of stigma and being misunderstood reflects the unawareness within wider society for the many expressions of dementia. This is reflected also in the lack of voluntary organisations providing support for those affected by DLB, compared with for example $\mathrm{AD}$, in many parts of the world. In view of the historically negative connotations of the dementia term, one initial step to increase public awareness could be to transition to using neurocognitive disorders, as suggested by the DSM-V. ${ }^{49}$

\section{CONCLUSIONS}

This study demonstrates for the first time the feasibility in conducting in-depth interviews with persons with DLB, and outlines areas of importance for the disease experience. It was found that symptoms experienced were different to those in other types of dementia, resulting in distinctive physical, cognitive and social consequences. The overall disease experience and well-being were subsequently found to be dependent on self-perception and successful coping mechanisms, as well as the views and actions of those around the person. These findings have implications for both research and clinical practice, highlighting the importance of direct involvement of DLB persons in identifying suitable healthcare interventions. The aspiration is that this can inspire future work, such as exploring the patient perspectives on pharmacological and non-pharmacological management of disease.

Acknowledgements The authors are grateful to the participants for taking part in these interviews. Many thanks also to Ingrid Fioretos, Eva Granvik and Andreas Jönsson for contributing with comments to this manuscript.

Contributors EL conceived the study. Data analysis was done by VL, AH-L, ELS and EL, with interpretation supported by GT. The initial manuscript draft was prepared by VL, with critical revisions for intellectual content by ELS, AH-L, GT and EL. The final version was approved by all authors.

Funding This study was financed by the Swedish Research Council (Vetenskapsrådet no. 523-2010-520) and Regional Funding provided by the Southern Health Care Region (Södra sjukvårdregionen). 
Disclaimer All researchers acted independently to the funding bodies. The funding agencies had no role in study design; in the collection, analysis and interpretation of data; in the writing of the report; or in the decision to submit the article for publication.

Competing interests None declared.

Patient consent Obtained.

Ethics approval This study was approved by the local institutional review board (IRB) in Lund, Sweden (dnr 2015/895).

Provenance and peer review Not commissioned; externally peer reviewed.

Data sharing statement № additional data are available.

Open access This is an open access article distributed in accordance with the Creative Commons Attribution Non Commercial (CC BY-NC 4.0) license, which permits others to distribute, remix, adapt, build upon this work non-commercially, and license their derivative works on different terms, provided the original work is properly cited, appropriate credit is given, any changes made indicated, and the use is non-commercial. See: http://creativecommons.org/licenses/by-nc/4.0/.

\section{REFERENCES}

1. Prince M, Wimo A, Guerchet M, et al. The global impact of dementia. an analysis of prevalence, incidence, costs and trends. London: World Alzheimer Report, 2015.

2. Vann Jones SA, O'Brien JT. The prevalence and incidence of dementia with Lewy bodies: a systematic review of population and clinical studies. Psychol Med 2014;44:673-83.

3. McKeith IG, Boeve BF, Dickson DW, et al. Diagnosis and management of dementia with Lewy bodies: fourth consensus report of the DLB Consortium. Neurology 2017;89:88-100.

4. Boot BP. Comprehensive treatment of dementia with Lewy bodies. Alzheimers Res Ther 2015;7:45.

5. Svendsboe E, Terum T, Testad I, et al. Caregiver burden in family carers of people with dementia with Lewy bodies and Alzheimer's disease. Int J Geriatr Psychiatry 2016;31:1075-83.

6. Boström F, Jönsson L, Minthon L, et al. Patients with dementia with lewy bodies have more impaired quality of life than patients with Alzheimer disease. Alzheimer Dis Assoc Disord 2007;21:150-4.

7. Zweig YR, Galvin JE. Lewy body dementia: the impact on patients and caregivers. Alzheimers Res Ther 2014;6:21.

8. Stinton C, McKeith I, Taylor JP, et al. Pharmacological management of Lewy body dementia: a systematic review and meta-analysis. Am $J$ Psychiatry 2015;172:731-42.

9. Galvin JE, Duda JE, Kaufer DI, et al. Lewy body dementia: caregiver burden and unmet needs. Alzheimer Dis Assoc Disord 2010;24:177-81.

10. Galvin JE, Duda JE, Kaufer DI, et al. Lewy body dementia: the caregiver experience of clinical care. Parkinsonism Relat Disord 2010;16:388-92.

11. Ricci M, Guidoni SV, Sepe-Monti M, et al. Clinical findings, functional abilities and caregiver distress in the early stage of dementia with Lewy bodies (DLB) and Alzheimer's disease (AD). Arch Gerontol Geriatr 2009;49:e101-4.

12. Leggett AN, Zarit S, Taylor A, et al. Stress and burden among caregivers of patients with lewy body dementia. Gerontologist 2011;51:76-85.

13. Górska S, Forsyth K, Maciver D. Living with dementia: a metasynthesis of qualitative research on the lived experience. Gerontologist 2018;58:gnw195.

14. de Boer ME, Hertogh CM, Dröes RM, et al. Suffering from dementia - the patient's perspective: a review of the literature. Int Psychogeriatr 2007;19:1021-39.

15. Caddell LS, Clare L. The impact of dementia on self and identity: a systematic review. Clin Psychol Rev 2010;30:113-26.

16. O'Brien BC, Harris IB, Beckman TJ, et al. Standards for reporting qualitative research: a synthesis of recommendations. Acad Med 2014;89:1245-51.

17. McKeith IG, Dickson DW, Lowe J, et al. Diagnosis and management of dementia with Lewy bodies: third report of the DLB Consortium. Neurology 2005;65:1863-72.

18. Savica R, Grossardt BR, Bower JH, et al. Survival and causes of death among people with clinically diagnosed synucleinopathies with parkinsonism. JAMA Neurol 2017;74:839-46.

19. Folstein MF, Folstein SE, McHugh PR. "Mini-mental state". A practical method for grading the cognitive state of patients for the clinician. J Psychiatr Res 1975;12:189-98.
20. Logsdon RG, Gibbons LE, McCurry SM, et al. Quality of life in Alzheimer's disease: patient and caregiver reports. Journal of Mental Health and Aging 1999;5:21-32.

21. Cridland EK, Phillipson L, Brennan-Horley C, et al. Reflections and recommendations for conducting in-depth interviews with people with dementia. Qual Health Res 2016:1774-86.

22. Moore TF, Hollett J. Giving voice to persons living with dementia: the researcher's opportunities and challenges. Nurs Sci $Q$ 2003;16:163-7.

23. Smith JA, Flowers P, Larkin M. Interpretative phenomenological analysis: theory, method and research. Los Angeles, CA: SAGE, 2009.

24. Braun V, Clarke V. Using thematic analysis in psychology. Qual Res Psychol 2006;3:77-101.

25. Smith JA, Osborn M, Jarman M. Doing interpretative phenomenological analysis. In: Murray M, Chamberlain K, eds. Qualitative health psychology: theories and methods. London: Sage, 1999.

26. Patton MQ. Qualitative evaluation and research methods. 2nd ed. Newbury Park, CA: Sage, 1990.

27. Charmaz K. Loss of self: a fundamental form of suffering in the chronically ill. Sociol Health IIIn 1983;5:168-95.

28. Langdon SA, Eagle A, Warner J. Making sense of dementia in the social world: a qualitative study. Soc Sci Med 2007;64:989-1000.

29. Sabat SR, Harré R. The construction and deconstruction of self in Alzheimer's disease. Ageing Soc 1992;12:443-61.

30. Clare L. Managing threats to self: awareness in early stage Alzheimer's disease. Soc Sci Med 2003;57:1017-29.

31. Harman G, Clare L. Illness representations and lived experience in early-stage dementia. Qual Health Res 2006;16:484-502.

32. Hedman R, Hansebo G, Ternestedt BM, et al. How people with Alzheimer's disease express their sense of self: analysis using Rom Harré's theory of selfhood. Dementia 2013;12:713-33.

33. Mills MA. Narrative identity and dementia: a study of emotion and narrative in older people with dementia. Ageing Soc 1997;17:673-98.

34. Sabat SR, Collins M. Intact social, cognitive ability, and selfhood: a case study of Alzheimer's disease. Am J Alzheimers Dis 1999;14:11-19.

35. Sabat SR. Capacity for decision-making in Alzheimer's disease: selfhood, positioning and semiotic people. Aust N Z J Psychiatry 2005;39:1030-5.

36. Kitwood T. Dementia reconsidered: the person comes first. Buckingham: Open University Press, 1997.

37. Brittain K, Corner L, Robinson L, et al. Ageing in place and technologies of place: the lived experience of people with dementia in changing social, physical and technological environments. Sociol Health IIIn 2010;32:272-87.

38. Trigg R, Jones RW, Skevington SM. Can people with mild to moderate dementia provide reliable answers about their quality of life? Age Ageing 2007;36:663-9.

39. Livingston G, Cooper C, Woods J, et al. Successful ageing in adversity: the LASER-AD longitudinal study. J Neurol Neurosurg Psychiatry 2008;79:641-5.

40. Alzheimer's Society UK. My name is not dementia: literature review. London: Alzheimer's Society UK, 2010.

41. Hoe J, Cooper C, Livingston G. An overview of the LASER-AD study: a longitudinal epidemiological study of people with Alzheimer's disease. Int Rev Psychiatry 2013;25:659-72.

42. Group W. Development of the WHOQOL: rationale and current status. Int J Ment Health 1994;23:24-56.

43. Goins RT, Jones J, Schure M, et al. Older adults' perceptions of mobility: a metasynthesis of qualitative studies. Gerontologist 2015;55:929-42.

44. Olsson A, Lampic C, Skovdahl K, et al. Persons with early-stage dementia reflect on being outdoors: a repeated interview study. Aging Ment Health 2013;17:793-800.

45. Pörn I. Health and adaptedness. Theor Med 1993;14:295-303.

46. Fetherstonhaugh D, Tarzia L, Nay R. Being central to decision making means I am still here!: the essence of decision making for people with dementia. J Aging Stud 2013;27:143-50.

47. Bulpitt $\mathrm{H}$, Martin PJ. Who am I and what am I doing? Becoming a qualitative research interviewer. Nurse Res 2010;17:7-16.

48. Hindle JV, Watermeyer TJ, Roberts J, et al. Goal-orientated cognitive rehabilitation for dementias associated with Parkinson's disease-a pilot randomised controlled trial. Int J Geriatr Psychiatry 2018;33:718-28.

49. American Psychiatric Association. Diagnostic and statistical manual of mental disorders. Arlington, VA: American Psychiatric Association, 2013. 